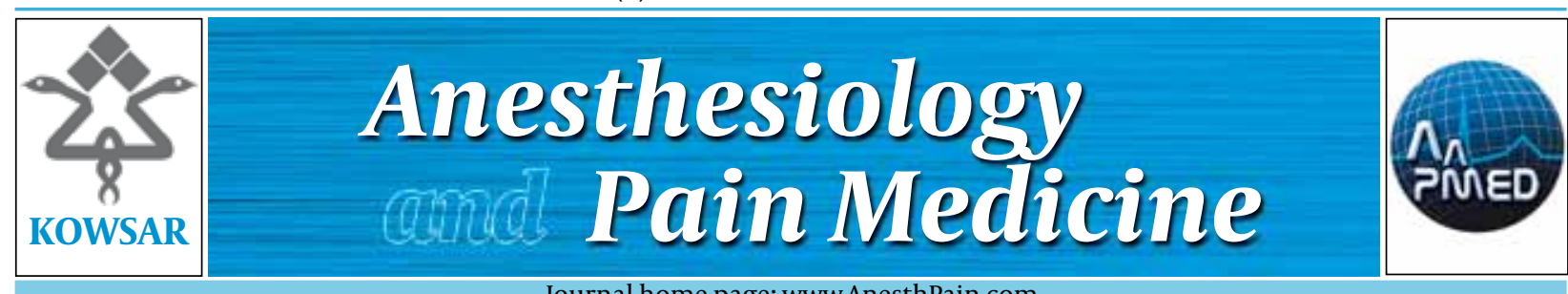

\title{
Tracheal Intubation Without Use of Muscle Relaxants: Comparison of Remifentanil and Alfentanil
}

\author{
Volkan Hanci $1^{*}$ \\ ${ }^{1}$ Department of Anesthesiology and Reanimation, School of Medicine, Canakkale Onsekiz Mart University, Canakkale, Turkey
}

\section{A R T I C L E I N F O}

Article type:

Letter to Editor

Article history:

Received: 22 Nov 2011

Revised: 24 Nov 2011

Accepted: 28 Nov 2011

\section{Keywords:}

Remifentanil

Alfentanil

Intubation

\section{Dear Editor,}

My objective is to analyze the efficiency of remifentanil-propofol and alfentanil-propofol combinations for laryngoscopic endotracheal intubation in the absence of muscle relaxants. This analysis reviews the work by Imani et al. (1). Muscle relaxants are frequently used to facilitate endotracheal intubation during anesthesia induction. However, the administration of short-acting depolarizing muscle relaxants is closely related to postoperative myalgias, malignant hyperthermia, hyperkalemia, and increased intracranial or intraocular pressure. Using non-depolarizing muscle relaxants may produce prolonged neuromuscular blockade, potentiate histamine release, increase the side effects from anticholinesterases used for reversing the agents, and lead to an inability to quickly reverse the blockade in the event of an unexpected difficult intubation. When using muscle relaxants is undesirable or contraindicated, it is important to administer other, proper induction agents to provide good intubating conditions $(1,2)$. Studies have investi-

${ }^{*}$ Corresponding author: Volkan Hanci, Department of Anesthesiology and Reanimation, School of Medicine, Canakkale Onsekiz Mart University, Canakkale, Turkey.Tel:+90-5306433240, Fax:+90-2862635956,E-mail:vhanci@gmail.com

DOI:10.5812/kowsar.22287523.3599

Copyright $\odot 2012$ Kowsar M.P.Co. All rights reserved.
- Please cite this paper as:

Hanci V. Tracheal Intubation Without Use of Muscle Relaxants: Comparison of Remifentanil and Alfentanil. Anesth Pain. 2012;1(3):210-11. DOI: 10.5812/kowsar.22287523.3599.

Copyright @ 2012 Kowsar M. P. Co. All rights reserved.

gated the use of propofol alone and propofol combined with other drugs (usually fentanyl, alfentanil, or remifentanil) for intubation without using a neuromuscular blockade; the findings have shown that intubation with all of these methods were successful (1-3). In another study, a dose of $2.5 \mathrm{mg} / \mathrm{kg}$ of propofol was applied without the use of a neuromuscular blockade, but only $20 \%$ of the patients had sufficient intubation scores (4). To decrease the necessary propofol dosage, eliminate unintented effects and to increase the potential of propofol's effectiveness, propofol is often used together with opioids for intubation without a neuromuscular blockade. It has been reported that intubation scores were insufficient in the $17 \%$ of patients who were given fentanyl $(1,5)$. Alfentanil combined with propofol for intubation without a neuromuscular blockade may cause muscle rigidity and, especially at high doses, may lead to cardiovascular depression. Additionally, prolonging the effect of alfentanil after short-term operations is also undesirable $(5,6)$. Remifentanil is a phenyl-piperidine derivative that was first introduced into clinical practice in 1996. Remifentanil is 20 to 30 times more potent than alfentanil and its elimination half life is 3.8-8.3 minutes. Compared to alfentanil, remifentanil's effect reduces much more quickly after intubation; this is an important advantage 
over alfentanil, especially in short-term and outpatient surgeries $(1,3,6)$.

However, studies on propofol-alfentanil and propofolremifentanil combinations are limited. Alexander et al. (7) compared the use of remifentanil $(2 \mu \mathrm{g} / \mathrm{kg})$, alfentanil (50 $\mu \mathrm{g} / \mathrm{kg}$ ), and succinylcholine (1 mg/kg) for intubation and found that perfect intubation scores were present in $35 \%, 85 \%$, and $100 \%$ of the patients, respectively. The authors emphasized that remifentanil was an unsuitable option for intubation without a neumuscular blockade. Using a child sample, another study compared the effects of $4 \mathrm{mg} / \mathrm{kg}$ of propofol and $0.2 \mathrm{mg} / \mathrm{kg}$ of lidocain with 15 $\mu \mathrm{g} / \mathrm{kg}$ of alfentanil or $1 \mu \mathrm{g} / \mathrm{kg}$ of remifentanil in intubation without a neuromuscular blockade. The findings revealed that neither the alfentanil nor remifentanil group caused a significant difference in intubation conditions (8). In a related study, Mohammadreza et al. (9) compared the effects of $5 \mathrm{mg} / \mathrm{kg}$ of thiopental with $40 \mu \mathrm{g} / \mathrm{kg}$ of alfentanil, $2 \mu \mathrm{g} / \mathrm{kg}$ of remifentanil, $3 \mu \mathrm{g} / \mathrm{kg}$ of remifentanil, and $4 \mu \mathrm{g} / \mathrm{kg}$ of remifentanil on intubation without a neuromuscular blockade. The authors reported that the best intubation conditions were available with $4 \mu \mathrm{g} / \mathrm{kg}$ of remifentanil and a combination of $40 \mu \mathrm{g} / \mathrm{kg}$ of alfentanil with $5 \mathrm{mg} / \mathrm{kg}$ of thiopental. Similarly, Klemola et al. (6) compared the effects of $2.5 \mathrm{mg} / \mathrm{kg}$ of propofol with 30 $\mu \mathrm{g} / \mathrm{kg}$ of alfentanil, $3 \mu \mathrm{g} / \mathrm{kg}$ of remifentanil, and $4 \mu \mathrm{g} / \mathrm{kg}$ of remifentanilin on intubation without a neuromuscular blockade. The authors reported that the best intubation conditions were given with the combination of $4 \mu \mathrm{g} / \mathrm{kg}$ of remifentanil and $2.5 \mathrm{mg} / \mathrm{kg}$ of propofol. In another similar study, Erhan ve ark (9) compared the effects of 2 $\mathrm{mg} / \mathrm{kg}$ of propofol with $40 \mu \mathrm{g} / \mathrm{kg}$ of alfentanil or 1, 2, 3, and $4 \mu \mathrm{g} / \mathrm{kg}$ of remifentanil on intubation without a neuromuscular blockade. The authors reported that the best intubation conditions were available with a combination of $4 \mu \mathrm{g} / \mathrm{kg}$ of remifentanil with $2 \mathrm{mg} / \mathrm{kg}$ of propofol. In a related study, Imani et al. (1) reported better intubation conditions with the combination of $5 \mu \mathrm{g} / \mathrm{kg}$ of remifentanil with $2 \mathrm{mg} / \mathrm{kg}$ of propofol than with $2 \mathrm{mg} / \mathrm{kg}$ of propofol, $50 \mu \mathrm{g} / \mathrm{kg}$ alfentanil, and $5 \mu \mathrm{g} / \mathrm{kg}$ of remifentanil. Nonhomogeneous distribution of doses, administration speed of agents, injection durations, time elapsed between injection and intubation, different scoring systems used for evaluation of intubation conditions, and age intervals of the cases enrolled in the studies all lead to difficulties in comparing these studies $(1,6-10)$. Some limitations are also present with Imani et al.'s study. First, they did not use a control group that received only propofol. In addition, the doses of remifentanil and alfentanil used in Imani et al.'s study are higher than in similar previous studies (6-10). As a result, the remifentanil-propofol combination seems to have advantages over the alfentanil-propofol combination because of the fast and short effect time of remifentanil. Nevertheless, evidencebased medical analyses, meta-analyses, and experimental studies with higher patient numbers are needed in this area.

\section{Financial Disclosure}

None.

\section{References}

1. Imani F, Alebouyeh MR, Taghipour-Anvari Z, Faiz SHR. Use of Remifentanil and Alfentanil in Endotracheal Intubation: A Comparative Study. Anesth Pain. 2011;1(2):61-5.

2. Hanci V, Erdogan G, Okyay RD, Yurtlu BS, Ayoglu H, Baydilek Y, et al. Effects of fentanyl-lidocaine-propofol and dexmedetomidine-lidocaine-propofol on tracheal intubation without use of muscle relaxants. Kaohsiung J Med Sci. 2010;26(5):244-50.

3. Erbay H, Serin S, Sungurtekin H, Hanci V, Gönüllü M. Comparison of Propofol with Two Different Remifentanil Doses Combinations in the Tracheal Intubation Without Muscle Relaxant. Turk Klinikleri J Anest Reanim. 2009;7(2):75.

4. Grange CS, Suresh D, Meikle R, Carter JA, Goldhill DR. Intubation with propofol: evaluation of pre-treatment with alfentanil or lignocaine. EurJ Anaesthesiol. 1993;10(1):9-12.

5. Jabbour-Khoury SI, Dabbous AS, Rizk LB, Abou Jalad NM, Bartelmaos TE, El-Khatib MF, et al. A combination of alfentanillidocaine-propofol provides better intubating conditions than fentanyl-lidocaine-propofol in the absence of muscle relaxants. Can JAnaesth. 2003;50(2):116-20.

6. Klemola UM, Mennander S, Saarnivaara L. Tracheal intubation without the use of muscle relaxants: remifentanil or alfentanil in combination with propofol. Acta Anaesthesiol Scand. 2000;44(4):465-9.

7. Alexander R, Booth J, Olufolabi AJ, El-Moalem HE, Glass PS. Comparison of remifentanil with alfentanil or suxamethonium following propofol anaesthesia for tracheal intubation. Anaesthesia. 1999;54(11):1032-6.

8. Robinson DN, O'Brien K, Kumar R, Morton NS. Tracheal intubation without neuromuscular blockade in children: a comparison of propofol combined either with alfentanil or remifentanil. Paediatr Anaesth. 1998;8(6):467-71.

9. Mohammadreza S, Azim H. Tracheal intubation without muscle relaxants: a randomized study of remifentanil or alfentanil in combination with thiopental. Ann Saudi Med. 2008;28(2):89-95.

10. Erhan E, Ugur G, Alper I, Gunusen I, Ozyar B. Tracheal intubation without muscle relaxants: remifentanil or alfentanil in combination with propofol. EurJ Anaesthesiol. 2003;20(1):37-43. 